\title{
Inovasi Alat Musik Konvensional Berbahan Dasar Bambu Oleh Indonesian Bamboo Community
}

\author{
Mirna Nurmala \\ Pasca Sarjana Institusi Seni dan Budaya Indonesia \\ Jl. Buah Batu No. 212 Bandung \\ mirnanurmal@gmail.com
}

\begin{abstract}
ABSTRAK
Adanya asumsi bahwa bambu merupakan material dasar yang murah dan tidak memiliki harga jual,memicu kegelisahan beberapa kalangan untuk berinovasi menggunakan bambu sebagai bahan dasar. Salah satunya adalah Indonesian Bamboo Community yang dipimpin oleh Adang Muhidin yang mencoba berinovasi dengan membuat alat musik konvensional berbahan dasar bambu. Tulisan ini akan membahas proses kreatif yang dilakukan oleh sebuah komunitas bambu dengan metode penelitian kualitatif, yaitu penelitian yang menekankan pada kualitas atau hal terpenting dari sifat suatu benda, yang didalamnya tidak hanya meliputi pertunjukan musik saja tapi bagaimana membuat alat musik yang berbahan dasar bambu.
\end{abstract}

Kata Kunci : Bambu, Inovasi, Indonesian Bamboo Community.

\begin{abstract}
The assumption that bamboo is a material cost basis and does not have a selling price, triggers anxiety in some quarters to innovate using bamboo as raw material. One of them is the Indonesian Bamboo Community led by Adang Muhidin who tried to innovate by creating a conventional musical instrument made from bamboo. This paper will discuss the creative process undertaken by a community of bamboo with qualitative research methods, the research emphasizes on the quality or the most important thing of the nature of an object, in which not only includes music performances alone but how to make a musical instrument made from bamboo.
\end{abstract}

Keywords: Bamboo, Innovation, Indonesian Bamboo Community

\section{A. Pendahuluan}

Dewasa ini, banyak perbincangan tentang upaya hidup hemat energi, ramah lingkungan, atau tindakan go green sebagai wujud peduli terhadap global warming atau pemanasan global. Indonesia merupakan salah satu negara yang sangat diharapkan sebagai paru-paru dunia untuk mencegah terjadinya pemanasan global, ada berbagai macam tumbuhan yang dapat tumbuh subur disini, salah satunya tanaman bambu. Bambu merupakan salah satu tanaman yang ramah terhadap lingkungan, tanaman bambu secara alami dapat menjaga keseimbangan alam dan lingkungannya, selain dapat menghasilkan oksigen yang menjadikan udara sekitar menjadi lebih bersih dan segar, juga dapat menyeimbangkan keberadaan tanah yang menyebabkan erosi, longsor, dan banjir. Untuk kesuburan air pun, tanaman bambu memiliki kontribusi yang sangat tinggi, karena akar pohon bambu akan menyerap, menyimpan, dan mengalirkan melalui mata air secara langsung. Ada banyak jenis tanaman bambu yang berada di Indonesia, yang bisa diman- faatkan sebagai hasil produk untuk kehidupan manusia, namun setiap jenis memiliki karakteristik dan fungsi masing-masing.

Bambu merupakan salah satu hasil bumi yang tumbuh subur di Indonesia dan mudah didapatkan. Bambu diklasifikasikan ke lebih dari 10 genus dan 1450 spesies. Di Indonesia ditemukan sekitar 60 jenis dan bambu banyak ditemukan di dataran rendah sampai pegunungan dengan ketinggian sekitar 300 $\mathrm{m}$ diatas permukaan laut. Pada umumnya ditemukan ditempat-tempat terbuka dan daerahnya bebas dari genangan air. Dari kurang lebih 1.000 species bambu dalam 80 genera, sekitar 200 species dari 20 genera ditemukan di Asia Tenggara (Dransfield dan Widjaja, 1995). Bambu banyak digunakan sebagai bahan dasar alat-alat rumah tangga atau kerajinan tangan yang harga jualnya tidak terlalu tinggi, contohnya taraje ${ }^{1}$, kursi, meja, ayakan ${ }^{2}$, atau kadang-kadang ditemui berbaris membentuk suatu garis pembatas dari suatu wilayah desa yang identik dengan batas desa. Di Jawa, penduduk sering menanam bambu disekitar rumahnya dicampur 
dengan tanaman lain untuk berbagai keperluan. Di Indonesia bambu bisa dijadikan bahan dasar membuat alat musik tradisional, salah satunya angklung, suling, dan calung. Namun alat musik tersebut berbentuk statis sesuai dengan bentuk asli dari bambu yaitu bulat. Hal tersebut disebabkan bambu mempunyai keterbatasan dalam penggunaannya seperti, sifat fisik sehingga sukar dikerjakan secara mekanis, ukurannya bervariasi dan tidak seragam panjang ruasnya serta mudah terserang hama perusak kayu bubuk, rayap dan jamur. Sering ditemui barang-barang yang berasal dari bambu umumnya yang sudah dibuang kulitnya dan dalam keadaan basah mudah diserang oleh jamur biru dan berjamur. Begitu pula bambu bulat utuh dalam keadaan kering yang terserang serangga bubuk kering dan rayap kayu kering. Hal ini membuat anggapan negatif tentang bambu, sehingga bambu diidentikan dengan kemiskinan.Beberapa hasil penelitian menunjukkan bahwa dengan teknologi dan rekayasa, bambu dapat diproduk dalam berbagai bentuk dengan kekuatan yang tidak kalah dengan kayu. Hasil produknya dapat berbentuk balok, papan dalam ukuran yang tidak terbatas sehingga memudahkan pengguna dalam memanfaatkannya. Dalam konstruksi produk ini dapat dipakai sebagai bahan bangunan struktural dan non-struktural dalam bentuk bahan komposit. Bambu sebagai bahan pengganti kayu yang sekaligus dapat menyelamatkan dunia dari kerusakan hutan, akan sangat berperan pada tahun mendatang mengingat keberadaan kayu yang semakin berkurang.

Indonesian Bamboo Community memiliki pemikiran untuk membudidayakan bambu, mereka mencoba berinovasi membuat alat musik konvensional berbahan dasar bambu, tujuannya adalah agar bambu "naik kelas" ungkap Adang Muhidin ${ }^{3}$ selaku founder komunitas tersebut. Adang beserta tim melakukan research atau penelitian bagaimana membuat alat musik seperti gitar, biola, dan drum dengan bentuk yang tidak menghilangkan karateristik bambu.Berawal dari kecemasan bahwa Indonesia salah satu negara penghasil bambu terbesar didunia namun tidak banyak hasil produksi olahan bambu yang bisa dijual dengan harga yang layak dan dibudiyakan sebagai hasil kreatif yang memiliki nilai jual tinggi. Pengalaman pribadi Adang Muhidinketika melanjutkan studinya di German, di negara tersebut pembangunan dan pembudidayaan bambu sangat diutamakan dan dihargai dengan sangat mahal, bahkan pengembangan teknologi disana salah satunya menggunakan bambu. Untuk mempermudah peneliatian penulis memilih metode penelitian yaitu metode penelitian kualitatif, yang dilakukan secara langsung aktivitas Indonesian Bamboo Community dan wawancara dengan narasumber, pengolahan data akan dilakukan dengan metode analisis sintetis, atau keterkaitan hasil yang terlihat oleh alat indra dan wawasan secara empirik. Untuk membatasi pembahasan maka penulis mengambil sebuah teori tentang kreativitas yang dikemukakan oleh Dedi Supriadi (1994:7) merupakan kemampuan seseorang untuk melahirkan sesuatu yang baru, baik berupa gagasan maupun karya nyata, yang relatif berberda dengan apa yang telah ada sebelumnya.

\section{B. Pembahasan}

\section{Tanaman Bambu untuk Membuat Alat Musik}

Tanaman bambu umumnya tumbuh membentuk rumpun, akan tetapi bambu juga dapat hidup secara soliter. Pada beberapa jenis tertentu, bambu memiliki percabangan yang sangat banyak dan membentuk perdu, ada pula bambu yang memiliki kemampuan memanjat, bambu yang tergolong besar dan tegak berasal dari species Bambusa sp, Dendrocalamus spp, dan Gigantocholoa spp. Normalnya pertumbuhan bambu lurus ke atas dan ujung batanya melengkung karena menopang berat daun. Tinggi tanaman bambu berkisar antara $0,3-30 \mathrm{~m}$ dengan diameter batang $0,25-25 \mathrm{~cm}$ dan ketebalan dindingan mencapai $25 \mathrm{~mm}$. Batang bambu berbentuk silinder yang terdiri dari banyak ruas/buku-buku dan berongga pada setiap ruasnya. Pada saat usia tanaman bambu masih muda, batang cenderung lunak dan diselimuti semacap pelepah mulai dari pangkal hingga ujung batang. Setelah usia tanaman bambu dewasa, batang bambu menjadi lebih keras dan pelepah tersebut mengering sehingga lepas satu persatu dari setiap ruas bambu. Lingkungan merupakan salah satu faktor penting yang sangat mempengaruhi pertumbuhan bambu, iklim dan jenis tanah menjadi faktor penting. Di Indonesia tanaman bambu dapat tumbuh secara meluas baik di dataran rendah ataupun tinggi, tanaman bambu menyukai tempat yang terbuka dan terkena sinar matahari.

Tanaman bambu dapat dapat tumbuh di berbagai tipe iklim, mulai dari tipe curah hujan A sampai E menurut Schmidt Fergusson atau dari iklim basah sampai iklim kering. Bambu membutuhkan banyak air untuk pertumbuhannya, oleh karena 
itu semakin basah tipe iklimnya semakin banyak jenis bambu yang dapat tumbuh dengan baik dan subur di lingkungan tersebut. Curah hujan yang dibutuhkan tanaman bambu minimal $1.020 \mathrm{~mm}$ per tahun, dan memiliki kelembaban udara minimal 80 $\%$, kemudian memiliki suhu berkisar $8,8-36^{\circ} \mathrm{C}$. Bambu dapat tumbuh dengan kondisi tanah yang beragam, mulai dari tanah yang berat sampai tanah yang ringan. Di Indonesia tanah yang baik untuk pertumbuhan bambu yaitu jenis tanah campuran antara latosol coklat dengan regosol kelabu, serta andosol coklat kekuningan. Tanaman bambu dapat tumbuh dengan baik pada tanah yang memiliki pH 5,0 - 6,5 . pada tanah yang subur bambu akan tumbuh dengan baik karena asupan makanan bagi bambu dapat terpenuhi.

Bambu merupakan tanaman yang memiliki banyak manfaat. Semua bagian tanaman bambu dimulai dari akar, batangm daun dan rebungnya dapat dimanfaatkan untuk berbagai macam keperluan. Akar bambu berfungsi sebagai penahan erosi oleh karena itu bambu banyak ditemukan dan ditanam di pinggiran sungai atau di tanah yang berlereng curam, akar tanaman bambu juga dapat menjadi filter terhadap keberadaan limbah yang beracun. Akar-akar yang berserabut berfungsi menyaring air yang terkontaminasi limbah beracun, selain itu akar bambu dapat mingikat butir-butir air dalam tanahsehingga keberadaan rumpun bambu sering memunculkan sumber-sumber mata air. Bagian batang bambu paling banyak dimanfaatkan untuk kebutuhan manusia seperti bangunan, kerajinan dan bahat pembuat perkakas rumah tangga. Batang bambu yang sudah terbelah-belah atau dalam keadaan utuh tetap bisa dimanfaatkan. Kemudian daun bambu di pedesaan sering dimanfaatkan sebagai alat pembungkus makanan, daun bambu muda biasanya sering digunakan sebagai obat bagi yang gelisah dan sulittidur, dan daun bambu yang sudah kering dapat dijadikan sebagai kompos dan digunakan sebagai media tanaman khususnya jenis paku-pakuan. Rebung bambu merupakan tunas bambu muda yang muncul dari dalam tanah yang tumbuh dari rimpang/rhizoma bambu. Rebung dapat dimanfaatkan sebagai bahan sayuran segar yang dikemas dan diawetkan sebagai sayuran kaleng, rebung yang enak untuk dikonsumsi adalah jnis bambu anter dan bambu betung.

Bambu yang tunbuh di Indonesia sangat beragam dan memiliki kelebihan, disebabkan oleh faktor-faktor lingkungan dan tanah yang subur, jenis-jenisnya antara lain :

1. Awi ${ }^{4}$ duri atau bambu duri : Tumbuh di lahan yang basah (tepi sungai) dan daerah kering

2. Bambu tutul atau awi tutul: Tumbuh di tanah beriklim kering di dataran rendah, peruntukan, kerajinan tangan dan furnitur.

3. Awi ampel, haur yang berwarna kuning disebut haur koneng: Tumbuh di daerah yang kering atau lembab dan dapat tumbuh di daerah yang tergenang air selama $2-3$ bulan.

4. Awi Tela atau awi Lengka atau Bambu Lengka Tali: Tumbuh di dataran rendah hingga tinggi dan di daerah tropis rendah. peruntukan, untuk membuat keranjang sayur/buah dan rebung (makanan).

5. Awi Gombong atau bambu Gombong: Tumbuh di daerah tropis yang lembab, peruntukan, bahan bangunan dan alat musik tradisional

6. Awi mayan atau bambu mayan: Tumbuh di daerah lembab dan kering, peruntukan, tempat air. alat musik tradisional, sumpit, rebung

7. Awi Tamiyang atau Bambu Suling: Tumbuh di daerah yang curah hujannya tinggi, hutan tropis, lereng bukit, peruntukan, kerajinan tangan dan alat musik suling

8. Awi Jepang atau Bambu Jepang atau Bambu Bangkok : Tumbuh di dataran rendah dan tinggi

Namun tidak semua jenis tanaman bambu bisa dijadikan sebagai bahan dasar membuat alat musik. Ada kriteria khusus bagi jenis tanaman bambu yang bica menjadi bahan dasar membuat alat musik. Salah satu jenis tanaman bambu yang bisa menjadi alat musik antara lain :

1. Bambu Apus secara ilmiah bernama Gigatochloa apus $B l$, Ex (Schult.f) Kurz, dikenal juga dengan nama bambu tali atau awi tali, bambu ini umumnya membentuk rumpun rapat. Bambuu apus memiliki tinggi mencapai $20 \mathrm{~m}$ dengan warna batang hijau cerah sampai kekuning-kuningan, batang tidak bercabang dibagian bawah, memiliki diameter 2,5-15 cm, ketebalan dinding 3-15 $\mathrm{mm}$, panjang ruas $45-65 \mathrm{~cm}$. Dalam satu pohon, batang yang dapat dimanfaatkan antara $3-15 \mathrm{~m}$. Bambu apus memiliki batang yang sangat teratur, buku-bukunya terlihat ada penojolan dan berwarna kekuningan dengan bulu-bulu halus yang menempel disekitar buku-buku berwarna coklat kehitaman. Pelepah batang tidak mudah lepas meskipun umur batang sudah tua. Bambu apus diduga berasal dari daerah Burma dan sekarang tersebar luas di seluruh kepulauan Indonesia, 
jenis ini tumbuh subur di dataran rendah tetapi dapat juga tumbuh pegunungan sampai ketinggian $1.000 \mathrm{~m}$, bambu ini diperbanyak dengan rimpang atau potongan buluhnya. Bambu apus memiliki batang yang kuat, lit dan lurus.bambu apus dalam keadaan basah berwarna hijau dan tidak keras, ketika kering berubah menjadi kekuning-kuningan dan tidak mudah putus

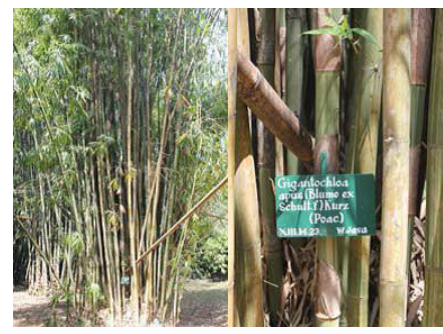

1.1 Gambar bambu apus

2. Bambu Ater secara ilmiah bernama Gigantochioa atter (Hassk) Kurz ex Munro. dikenal juga dengan nama awi temen, pring jawa, pring legi, dan pereng keles. Memiliki batang berwarna iju sampai hijau helap dengan diameter 5 - 10 $\mathrm{cm}$ dan tebal dinding $8 \mathrm{~mm}$, memiliki panjang ruas antara $40-50 \mathrm{~cm}$ dengan tinggi mencapai $22 \mathrm{~m}$. Pelepah batang mudah gugur, ruas-ruas tampak rata dengan garis putih melingkar pada pelepah. Jenis bambu ater tumbuh dengan subur di dataran rendah, namun sesekali ditemukan di dataran tinggi pada ketinggian $750 \mathrm{~m}$ dpl. Selain baik menjadi bahan untuk membuat alat musik, rebung bambu ater terkenal enak dan biasa dikonsumsi sebagai sayuran.

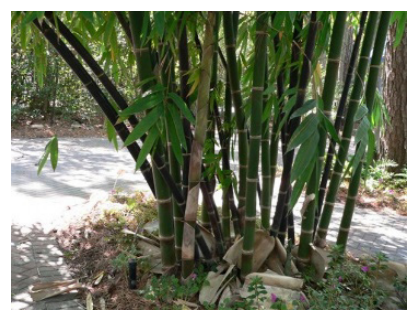

1.2 Gambar bambu ater

3. Bambu Hitam secara ilmiah bernama Gigantochloa atroviolancea Widj, dikenal juga dengan nama bambu wulung, pring ireng, atau awi hideung. Jenis ini disebut bambu hitam karena warna batng hijau kehitam-hitaman atau terkadang berwarna ungu tua. Rumpun bambu berwarna hitam jarang ditemukan, dan pertumbuhannya pun aga lambat. Memiliki buluh yang tegak dengan tinggi 20 m. Dengan ruas-ruas $40-50 \mathrm{~cm}$, tebal dinding 8 $\mathrm{mm}$ dam memiliki garis tengah $6-8 \mathrm{~cm}$. Bambu hitam bayang tumbuh di pulau Jawa dan di dataran rendah hingga ketinggian $650 \mathrm{~m} d \mathrm{~d}$. Di daerah Jawa Barat bambu ini banyak dipergunakan, selain untuk alat musik juga untuk kebutuhan bahan kerajinan dan furniture. Dalam keadaan basah tidak begitu keras, namun setelah kering sangat keras dan kuat, warnanya pun berubah menjadi hitam kecoklatan, daya lenturnya kurang hingga mudah pecah dan putus.

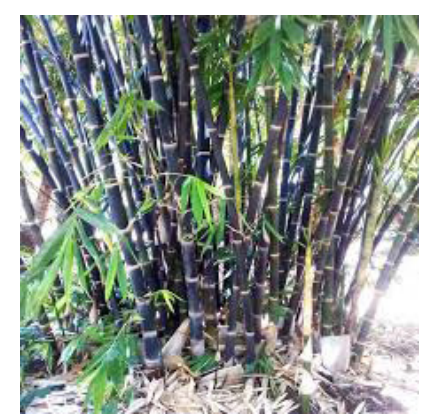

1.3 Gambar bambu hitam

4. Bambu betung dikenal dengan nama ilmiah Dendrocalamus asper (Schult. F.) Backer ex Heyne, yang memiliki nama lain awi bitung, pring petung dan pereng petong. Jenis bambu ini memiliki rumpun yang agak rapat, warna batang hijau kekuningkuningan, dengan ukuran dan tinggi yang lebih besar dibandingkan dengan bambu yang lain. Tinggi batang mencapai $20 \mathrm{~m}$ dengan diameter batang $20 \mathrm{~cm}$, ruas bambu betung cukup panjang dan tebal yaitu antara $40-60 \mathrm{~cm}$ dengan ketebalan $1-1,5 \mathrm{~cm}$. Jenis bambu ini mudah ditemukan didataran rendah, bambun ini akan tumbuh subur, terutama di daerah yang beriklim tidak terlalu kering. Bambu ini bersifat keras sehingga cocok digunakan untuk membuat alat musik.

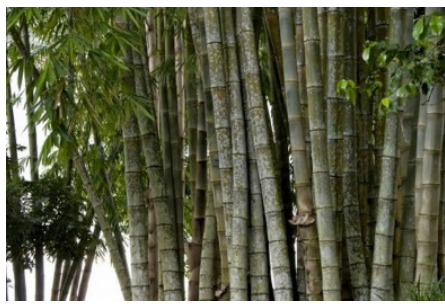

1.4 Gambar bambu betung

5. Bambu Gombong yang dikenal dengan nama ilmiah Dendrocalamus Giganteus Munro . Memiliki tinggi rata-rata $18 \mathrm{~m}$ dengan diameter batang bawah 10-15 cm, ketebalan bagian bawah 1-3cm, 
ketebalan batang bagian atas $0,3-0,7 \mathrm{~cm}$, memiliki jarak dari ruas ke ruas yang cukup panjang. Usia bambu yang baik untuk diolah sekitar 3 tahun.

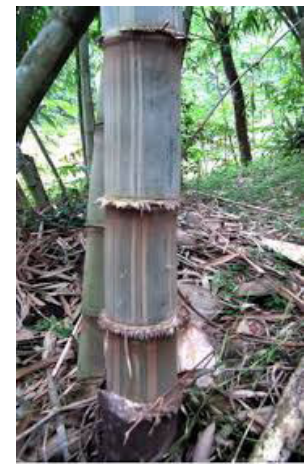

1.5 Gambar bambu gombong

Lima jenis tanaman bambu tersebut menurut hasil penelitiancocok untuk digunakan membuat alat musik bambu, karena memiliki struktur batang yang kuat dan cukup mudah ditemukan di Indonesia. Di Jawa Barat sendiri tanaman bambu tumbuh dengan subur dan banyak hasil produksi bambu yang diperjual belikan, sebagai daerah yang dikenal dengan alat musik angklungnya ini di Jawa Barat cukup banyak penggrajin alat musik angklung dan alat musik daerah lainnya yang terbuat dari bambu. Budidaya bambu selain bermanfaat dari sisi konservasi juga dapat memberikan keuntungan secara financial bagi masyarakat. Penjualan alat musik yang terbuat dari bambu khususnya angklung banyak diminati oleh masyarakat asing, hal tersebut dikarenakan keunikan dan kekhasan alat musik itu sendiri . Namun tidak hanya alat musik tradisional yang diminati oleh warga asing, produk alat musik konvensional seperti biola, gitar, bass, dan drum yang di produksi oleh komunitas kecil di daerah Cijerah Cimahi Jawa Barat bernama Indonesian Bamboo Community ini berhasil menarik pasar manca negara. Mereka berhasil menjual alat musik hasil kreativitas dan penelitian mereka ke mancanegara, mereka mencoba berani melakukan inovasi agar tujuan mereka aga "bambu naik kelas" bisa terlaksana ujar Adang Muhidin selaku founder komunitas tersebut.

\section{Indonesian Bamboo Community}

Indonesian Bamboo Community yang berdiri sejak tahun 2011 dan berlokasi di daerah Cijerah JL. Melong Asih No 23 Cimahi ini pada awalnya hanya berinovasi pada bentuk pertunjukan alat musik bambunya saja, dimana komunitas ini membentuk sebuah group musikyang mengelaborasi antara alat musik bambu tradisional seperti angklung, gambang arumba, dogdog, celempung dan lain-lain dengan alat musik konvensional pada umumnya seperti gitar, bass, drum, perkusi dan biola. Namun pada perkembangannya mereka mencoba berinovasi dengan membuat alat musik sendiri yang berbahan dasar bambu, terutama alat musik konvensionalnya. Inovasi pertama dilakukan oleh Abah Yudi selaku anggota Indonesian Bamboo Community pada waktu itu beliu membuat biola bambu dengan disign "primitif" atau berbentuk bambu utuh bulat tidak menghilangkan karakteristik asli bambu, namun disign ini masih memiliki banyak kekurangan dari segi suara atau tonal. Adang Muhidin selaku founder melakukan banyak hubungan dengan beberapa lembaga resmi untuk mengembangkan inovasi yang mereka lakukan. Kemudian Indonesian Bamboo Community atau yang lebih dikenal IBC ini melakukan kerjasama dengan beberapa lembaga pendidikan formal diantaranya ITB, ISBI dan Universitas Maranatha untuk melakukan penelitian lebih jauh mengenai cara membuat alat musik dengan disign dan perhitungan yang baik dan benar.

Komunitas ini memiliki strategi tersendiri untuk memperkenalkan alat musik hasil inovasi mereka, yaitu dengan cara memainkan alat musik tersebut dalam bentuk group musik profesional sebagai media promosi dan penelitian. Mereka membuat group musik yang dikemas secara modern tapi tetap memasukan unsur tradisional, awal tahun 2011 mereka membentuk group musik utama bernama Symphony Bamboo Essential. Group musik ini telah tampil dibeberapa panggung besar, salah satunya Festival Bambu Nusantara V pada tahun 2011, dan pada awal tahun 2013 di Jakarta Blues Festival. Namun group ini hanya bertahan selama satu setengah tahun, dikarenakan kesibukan antara personil lainnya. Pada akhir 2013 mereka membentuk formasi musik baru dengan anggotaanggota baru yang bernama D'bamboo Essential yang berjalan sampai saat ini. D'bamboo Essential berhasil mempromosikan alat musik hasil produksi IBC dengan cukup baik, selain mengisi acara di event-event daerah, dan nasional belum lama ini mereka unjuk gigi di event internasional, salah satunya World Harvest Festival di Kuching Sarawak Malaysia pada April 2015, Borneo Cultural Festival Agustus 2015 di Sibu Sarawak Malaysia, dan Yilan Internasional Art Festival 2016 di Taiwan. 


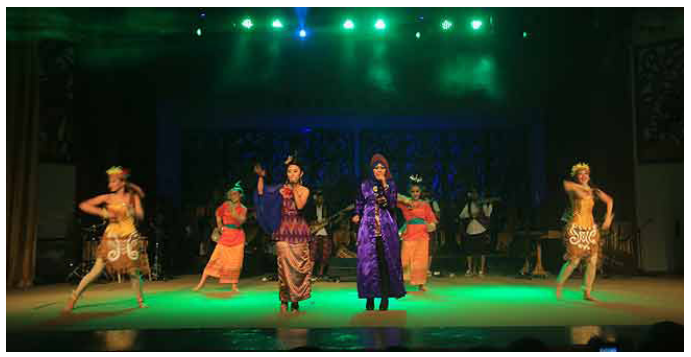

1.6 Gambar d'bamboo essential di world harvest festival

Indonesian Bamboo Community memiliki misi untuk menduniakan bambu, terutama hasil jasa dan produkkreatif anak bangsa agar bisa memberikan kontribusi bagi industri ekonomi kreatif bangsa Indonesia. Sejauh ini alat musik mereka telah tersebar dibeberapa negara, salah satunya biola bambu ke negara Jepang, Rumania, Amerika, Meksiko,Belgia, Taiwan, dan Perancis, sedangkan gitar, bass, dan drum ke negara Filipina, dan Malaysia. Hingga saat ini tim produksi IBC masih terus melakukan penelitian untuk terus mingkatkan kualitas, pada awal terbentuknya komunitas ini mereka melakukan penelitian dibantu oleh salah satu institusi sebagai tempat workshop, namun itu hanya berlangsung beberapa bulan, Adang Muhidin berusaha keras agar memiliki tempat workshop sendiri, yang akhirnya tercapai pada awal tahun 2014.

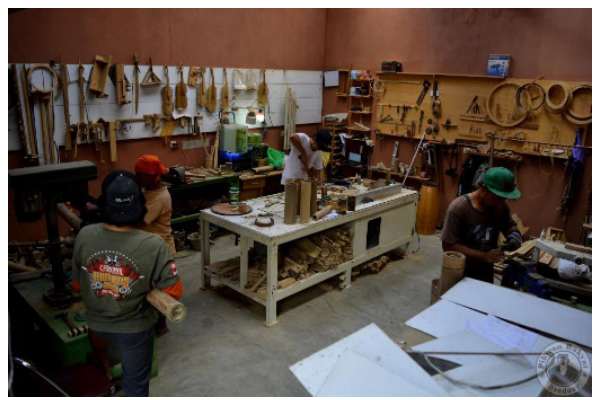

1.7 Gambar studio workshop IBC

Indonesian Bamboo Community mendapatkan bantuan dana dari salah satu bank negara untuk membangun tempat studio workshop, bantuan tersebut tidak berupa uang namun berupa alat-alat dan kepentingan untuk membuat alat musik dan pembangunan studio workshop. Peneliatian yang tim IBC lakukan berfokus pada pembudidayaan fungsi dan inovasi produk-produk bambu yang sudah ada. Selain membuat alat musik dari bambu, komunitas bambu ini membuat kerajinan lain yang terbuat dari bambu seperti gelas bambu, lampu, dan hingga kaos yang berbahan kain serat bambu. Namun IBC dikenal dengan inovasi alat musiknya karena hal tersebut belum banyak dilakukan oleh orang lain, terlebih lagi IBC tidak main-main dalam proses pembuatan sehingga banyak orang yang tertarik untuk datang dan membantu pergerakan komunitas ini.

Indonesian bamboo community berinovasi salah satunya dengan alat musik gitar. Tipe gitar yang diteliti komunitas ini yaitu gitar elektrik. Menurut hasil penelitian mereka ada beberapa jenis bambu yang memiliki struktur yang cocok untuk membuat gitar elektrik tipe chamber. Pada penelitian ini akan mengambil sample inovasi yang dilakukan IBC terhadap alat musik gitar, dimana secara bentuk dan hasil suara terjadi inovasi.

\section{Inovasi Gitar}

Setelah melakukan penelitian ada banyak sekali jenis bambu yang bisa digunakan untuk membuat alat musik, pada awalnya IBC menggunakan jenis bambu apapun untuk membuat alat musik, namun selama berjalannya waktu dan penelitian ada beberapa jenis bambu yang baik dan cocok untuk dijadikan bahan utama membuat alat musik konvensional terutama gitar dan biola menurut hasil penelitian IBC selama beberapa tahun ini. Jenis bambu bambu yang digunakan yaitu bambu gombong, bambu betung, bambu hitam, dan bambu apus atau tali. IBC membuat inovasi tipe gitar chamber dengan menggunakan bambu sebagai material utama dengan disain alami dari bentuk bambu itu sendiri. Bambu secara alamiah memiliki ruang yang berpotensi menjadi ruang akustik pada pembuatan gitar chamber.

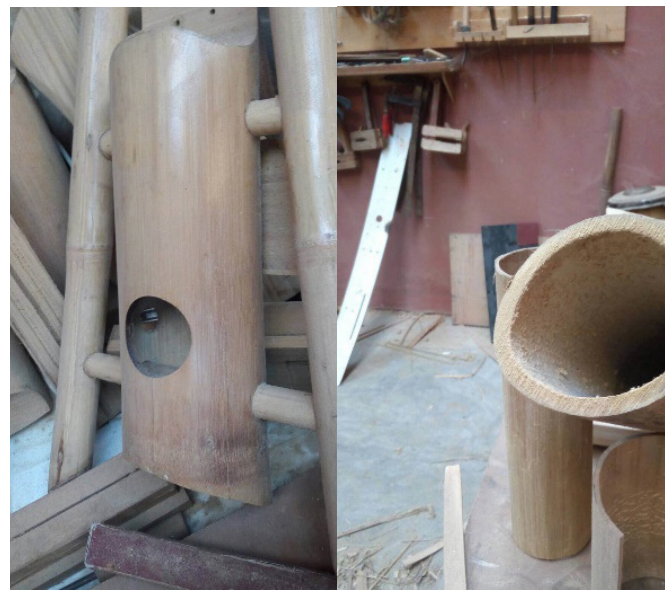

1.6 Gambar ruang akustik pada gitar bambu primitif desain IBC 
Pada gitar chamber kayu ruang akustik tidak dibuat secara alamiah, karena material kayu tidak memiliki ruang, maka ruang akustik dibuat secara perhitungan sestematik gitar chamber, seperti yang terlihat pada gambar berikt .

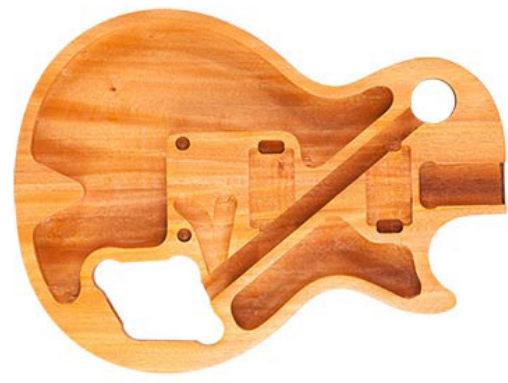

1.7 Gambar ruang akustik pada gitar chamber

Pada gitar chamber yang dibuat oleh tim IBC atau dinamakan Gitar Bambu Primitif Desain, bagian tubuh gitar terbuat dari bambu gombong bagian atas yang memiliki diameter $11-12 \mathrm{~cm}$. Bagian atas bambu gombong lebih cocok karena ketebalan bambu ideal untuk kebutuhan ruang akustik gitar chamber. Gitar bambu primitif desain ini memiliki bagian tubuh yang utuh diambil dari batang tanaman bambu yang mengalami proses pembentukan dan perhitungan yang mencoba disesuai dengan standar gitar chamber pada umumnya.Bentuk visual dari gitar bambu primitif berbeda dengan gitar chamber pada umumnya, hal tersebut dikarenakan pada gitar bambu ini memanfaatkan bentik asli dari bambu seperti yang bisa dilihat pada gambar berikut

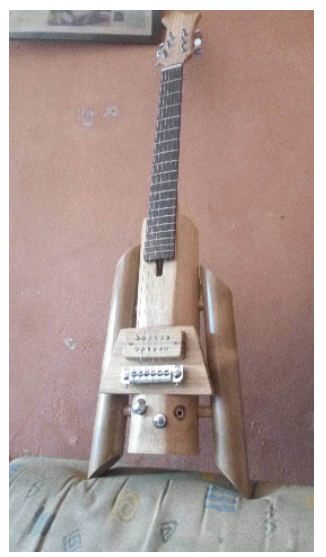

1.8 Gitar Bambu Primitif Desain

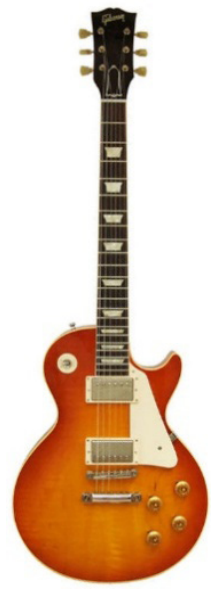

\subsection{Gitar Chamber Gibson}

Suara yang dihasilkan memiliki karakter yang berbeda, gitar bambu primitif memiliki karakter suara yang lebih kering atau cruch $^{5}$ dan flanger 6 . Menurutsalah satu tokoh gitar dan bass Harry Toledo selaku president Indonesian Bass Family , hasil suara dari gitar primitif jika digambarkan memiliki karakter suara yang unik, cenderung menghasilkan karakter chorus double place, dimana ada dua karakter suara yang berbeda keluar dalam satu waktu namun tetap terdengan bersih, hasil karakter suara tersebut keluar langsung dari gitar itu sendiri tanpa adanya penambahan efek gitar. IBC membuat inovasi ini sebagai upaya pengembangan dari gitar yang sudah ada, tidak bermaksud menjadikan perbandingan dengan gitar dengan karakter tertentu, karena setiap merk gitar sendiri memiliki karakter suara yang berbeda sesuai dengan keunggulan produk mereka.IBC berupaya membentuk karakter suara yang dihasilkan dari gitar yang terbuat dari bambu, salah satunya agar material bambu yang banyak dan mudah di temukan di Indonesia ini bisa dijadikan salah satu produk yang menjadi ciri khas Indonesia.

\section{Proses Membuat Gitar Bambu Primitif Desain}

Ada empat tahap pembuatan gitar bambu tipe ini, yaitu tahap proses pemilihan dan pengolahan bahan, kemudian proses pembuatan struktur gitar, proses finishing, dan terakhir proses setting. IBC menggunakan teknologi manual atau handmade ${ }^{7}$ menggunakan mesin hanya pada proses pemotongan bagian tertentu dan pengeboran. Berikut ini merupakan tahap-tahap pembuatan :

Proses pemilihan dan pengolahan : pada tahap ini peemilihan bambu sebagai bahan utama dilaku- 
kan, bambu yang dipakai yaitu bambu gombong untuk bagian tubuh gitar (body), dan bambu apus atau tali untuk bagian leher (neck), kemudian menggunakan bambu hitam untuk bagian sayap body. Bambu gombong yang digunakan dalam satu leunjeur ${ }^{8}$ yaitu bagian atas bambu karena ketebalan dan struktur dalam bambu sesuai untuk menghasilkan suara atau ruang akustik, bagian atas bambu yang digunakan berukuran $6 \mathrm{~m}$ berkisar $3-4$ buku dengan ketebalan kurang lebih $1-2 \mathrm{~cm}$, dan diameter $11-12 \mathrm{~cm}$. Usia bambu yang baik untuk digunakan berkisar 3 tahun, dan diusahakan tidak lebih dari usia 4 tahun karena protein yang dihasilkan jauh lebih banyak yang mengakibatkan rayap mudah berkembang. Bambu apus untuk membuat bagian leher dipilih dengan usia bambu yang sama begitu pula dengan bambu hitam. Bambu yang sudah dipilih kemudian dihaluskan dengan cara diampelas.

Proses pembuatan struktur gitar : pada proses ini dilakukan dua tahap yaitu pada bagian body dan sayap body kemudian bagian leher. Pada bagian body terbagi dua yaitu body chamber utama dan top plate menggunakan metode laminasi. Body chamber atau utama terbuat dari bambu gombong,berukuran $48 \mathrm{~cm}$, kemudian dihaluskan yang berfungsi untuk menghilangkan lapisan kulit luar bambu. Kemudian bagian atas dihilangkan dengan cara dipotong secara vertikal untuk bagian belakang gitar sepanjang $10 \mathrm{~cm}$ kemudian dihaluskan. Bagian tersebut ditutup menggunakan kulit bagian dalam bambu yang ditipiskan kurang lebih $3 \mathrm{~mm}$, bagian ini digunakan karena memiliki daya elastisitas yang lebih tinggi dibandingan bagian bambu lain, setelah itu direkatkan menggunakan lem putih kemudian diratakan. Bagian Top Plate Body menggunakan metode laminasi, bagian ini berfungsi untuk menempelkan pick up dan senar pada bagian akhir atau proses setting. Sayap body dibuat menggunakan bambu hitam dengan ukuran sayap bagian atas atau kiri gitar sepanjang $48 \mathrm{~cm}$ dan bagian bawah gitar atau kanan sepanjang $40 \mathrm{~cm}$. Bagian bawah memiliki ukuran yang lebih pendek agar janggauan tangan atau jari bisa sampai pada ujung fret board

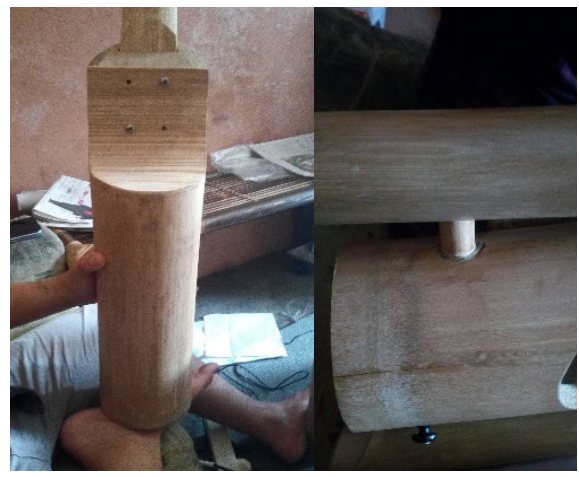

1.10 Gambar bagian belakang bambu yang telah ditutup dan sayap body

Setelah bagian body selesai kemudian membuat bagian neck yaitu dengan metode laminasi, metode laminasi yaitu menyatukan beberapa bagian bambu yang telah dibagi menjadi beberapa bagian dan menghasilkan bentuk yang rata. Pertama-tama potong bambu apus kurang lebih $67 \mathrm{~cm}$ kemudian belah bagian bambu apus menjadi delapan dan dihilangkan kulit bagian luar juga dalam bambu tersebut kemudian diserut hingga kurang lebih $2,5 \mathrm{~cm}$ menggunakan pisau irat untuk ketebalan neck gitar, lalu delapan bagian yang telah dibelah digabungkan dengan cara dilem dan diikat menggunakan karet bagian dalam ban setelah itu didiamkan selama kurang lebih 24 jam. Setelah kering kemudian diratakan permukaannya dengan cara dihaluskan. Bagian frat board dibuat menggunakan bambu dengan cara dilaminasi dan jarak frat disesuaikan dengan jarak frat gitar standar menggunakan metode manual tanpa mesin, panjang frat board yaitu $48 \mathrm{~cm}$. kemudian frat board dan neck gitar direkatkan. Untuk bagian head stock, lebar permukaan ditambahkan $1 \mathrm{~cm}$ dikanan dan $1 \mathrm{~cm}$ dikiri dan dibentuk sesuai dengan desain gitar bambu primitif menggunakan gergaji dan bagian pinggir dihaluskan dengan cara dikikir

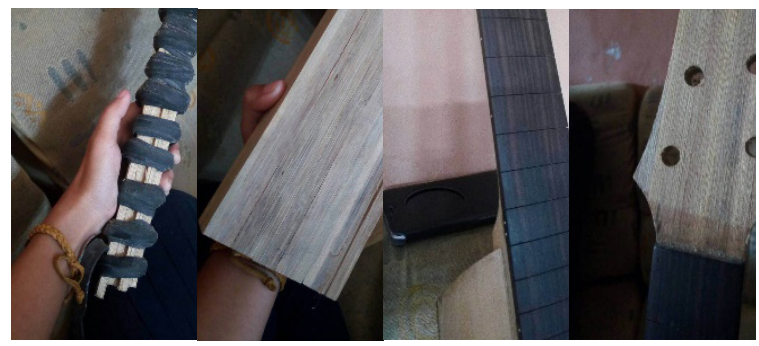

Gambar proses laminasi, hasil laminasi, hasil perekatan fret dengan neck, dan headstock gitar 
Proses finishing : tahap ini merupakan tahap yang berfungsi untuk melindungi seluruh bagian gitar, baik body maupun neck dengan cara mengoleskan seluruh bagian gitar menggunakan vernis kemudian didiamkan dengan suhu yang sama selama $48 \mathrm{jam}$. Bambu memiliki struktur yang rentan dengan rayap, proses vernis merupakan salah satu upaya pengawetan menggunakan bahan kimia. Bambu mudah dimasuki bahan pengawet dengan proses yang sederhana seperti difusi atau rendaman. Namun pada tahap ini setelah proses pembuatan struktur dan betuk gitar, proses finishing menggunakan vernis lebih cocok dan baik bagi gitar bambu.

Proses setting : tahap ini merupakan tahap terakhir dalam pembuatan gitar bambu primitif desain, yaitu menyatukan neck dengan body gitar dengan cara knockdown atau dikencangkan menggunakan baut, kemudian pemasangan sparepart gitar seperti bride, pick up, nut dan toning macine semua dipasang menggunakan baut, dan terakhir pemasangan senar yang dilanjutkan proses tuning gitar.

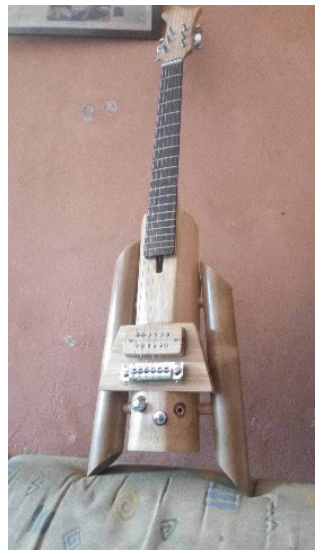

\subsection{GambarGitar Bambu Primitif Desain}

Langkah-langkah tersebut merupakan beberapa tahap dasar yang dilakukan untuk membuat gitar bambu primitif desain hasil inovasi berdasarkan penelitian tim Indonesian Bamboo Community. Selain mencoba berinovasi dengan jenis gitar chamber, IBC juga melakukan inovasi terhadap alat musik lain, seperti biola, bass, drum, dan perkusi. Hingga saat ini IBC masih terus melakukan evaluasi dan peneliatian agar mendapatkan hasil dan kualitas yang sempurna.

\section{Simpulan}

Paparan diatas menyajikan beberapa informasi tentang tentang tanaman bambu serta manfaat bambu dan inovasi yang bisa dilakukan untuk membuat alat musik konvensional, salah satunya yang dilakukan oleh komunitas yang berada di Bandung yaitu Indonesian Bamboo Community. Ada beberapa poin-poin yang bisa dijadikan acuan tentang bagaimana mencoba memanfaatkan bambu sebagai bahan dasar yang bisa digunakan sebagai bahan pengganti kayu yang saat ini sudah cukup sulit untuk didapatkan, dan memberikan pandangan lain mengenai kelebihan bambu dimana tanaman yang tumbuh subur di Indonesia ini bisa menjadi sumber daya untuk perindustrian dan ekonomi kreatif di Indonesia.

Inovasi yang dilakukan Indonesian Bamboo Community merupakan salah satu pergerakan yang dilakukan untuk memberikan pembelajaran agar lebih berani mencoba dan membuat sebuah kreativitas dengan cara yang positif dan sistematis. Penelitian yang dilakuan tim komunitas ini bisa menjadi salah satu langkah awal pengembangan insdustri alat musik daerah khususnya, umumnya industri alat musik nasional agar Indonesia tidak hanya memiliki alat musik tradisional dari bambu tetapi memiliki alat musik konvensional yang terbuat dari bambu sebagai khas negara.

\section{Catatan Akhir}

1 Tangga yang terbuat dari bambu (bahasa sunda) ${ }^{2}$ Salah satu alat rumah tangga yang berfungsi untuk menyaring beras dalam budaya sunda

${ }^{3}$ Merupakan founder dari Indonesian Bamboo Community sejak tahun 2011, beliau tinggal dan mengambil studi master jurusan metalurgi selama 2 tahun di salah satu universitas di Geman, dan selama 6 tahun bekerja disana.

${ }^{4}$ Istilah untuk tanaman bambu di daerah Jawa Barat atau Sunda

${ }^{5}$ Hasil suara cenderung lebih berkarakter middle high

${ }^{6}$ Hasil suara terdengar berkarakter lebihhigh

${ }^{7}$ Hasil karya buatan tangan manusia

${ }^{8}$ Satu batang besar tanaman bambu

\section{Daftar Pustaka}

Nur Tanjung, Banhdin dan H, Ardial. 2008. Pedoman Penulisan Karya Ilmiah (proposal, skripsi, dan tesis). Jakarta : Kencana Katalog Dalam Terbitan (KDT)

Graha, Oho. 1996. Seni Kerajinan Bambu. Bandung : Penerbit Angkasa 
Supriadi, Dedi. 1994. Kreativitas, Kebudayaan \& Perkembangan Iptek. Bandung: Penerbit Alfabeta

Widagdo. 2001. Desain dan Kebudayaan. Direktorat Jendral Pendidikan Tinggi Departemen Pendidikan Nasional

Sumardjo, Jakob. 2010. Estetika Paradoks Edisi Revisi. Sunan Ambu Press Sekolah Tinggi Seni Indonesia

Sony Kartika, Dharsono. 2007. Estetika. Bandung : Penerbit Rekayasa Sains

Aditanoyo, Teguh, Ayu Agustiani Putri, Hardistya. 2016. Karakterisasi Akustik Instrumen Musik Biola Berbahan Dasar Bambu. Skrisi Tugas Akhir Program Studi Teknik Fisika Fakultas Teknologi Industri Institusi Teknologi Bandung.

\section{Sumber Lain :}

Purwito, (2012). "Produk dari Bambu dan Turunannya". Makalah pada presentasi workshop rekonstruksi topic bumi village, sanggar kreatif anak bangsa, Ciputat Tangerang

Simbolon, Huyogo. (2016). Mengubah Nilai Bambu Ala Indonesian Bamboo Community [Online]. Tersedia : https://beritagar.id/artikel/laporankhas/mengubah-nilai-bambu-ala-indonesianbamboo-community. Html [16 Januari 2016]

Muhidin, Adang. (2016). Indonesian Bamboo Community. [Online]. Tersedia:

https://www.facebook.com/bambuindonesia/. Html [Januari 2011]

Kementrian Kehutanan Badan Penyuluhan dan Pengembangan SDM Kehutanan Pusat Penyuluhan (2012). Mau Tahu Tentang Bambu?. Materi Penyuluhan Keutanan

Purajatnika S, Pon (2016). Penerapan Perwujudan Sunda Pada Arsitektur Bambu. Materi Seminar. Moerdomo Learning Initiative, Perpustakaan ITB Bandung

Hermawan, Deni (2014). Metode Penelitian Lapangan. Modul Pembelajaran Prodi Penciptaan dan

Pengkajian Seni, Pascasarjana STSI Bandumg.
Herdini, Heri (2014). Metode Penelitian dan Penciptaan Seni. Modul Pembelajaran Prodi Penciptaan dan

Pengkajian Seni, Pascasarjana STSI Bandumg.

Muhidin, Adang (2016). Wawancara Founder Indonesian Bamboo Community.

Harpiana, Ronal (2016). Wawancara Penanggung Jawab Defisi Produksi Gitar Indonesian Bamboo Community

\section{Artikel Jurnal Terkait :}

Pramoko. (2016). "Kreasi Unik Gitar Bambu”. Majalah Natasha. (3), 59-60.

2004. Jurnal Pendidikan dan Kebudayaan. Vol ke-10 No 048. Jakarta : Badan Penelitian dan Pengembangan Departemen Pendidikan Nasional

2015. Jurnal Panggung (Pendidikan, Metode san Aplikasi Seni). Vol.25 No.2. Bandung : Institusi Seni dan Budaya Indonesia

2014. Jurnal Pendidikan dan Kebudayaan. Vol. 20 No.2. Jakarta : Badan Penelitian dan Pengembangan Departemen Pendidikan Nasional

2007. Jurnal Seni Musik (Seni Musik Ditinjau dari Kajian Ilmiah). Vol.4 No.1. Tangerang Jurusan Seni Musik-Fakultas Ilmu Seni Universitas Pelita Harapan.

2014. Jurnal Musik Bambu. Vol 01, No 1. Bandung : Prodi Musik Bambu STSI Bandung 